\title{
A new species of Falsocis (Coleoptera: Ciidae) from the Atlantic Forest biome with new geographic records and an updated identification key for the species of the genus
}

\author{
Lucimar Soares de Araujo $^{1^{*}}$ \& Cristiano Lopes-Andrade ${ }^{1}$
}

\author{
'Laboratório de Sistemática e Biologia de Coleoptera, Departamento de Biologia Animal, Universidade Federal de \\ Viçosa. Campus, 36570-900, Viçosa, MG, Brazil. \\ *Corresponding author: E-mail: lucimar.araujo@gmail.com
}

\begin{abstract}
Species of Falsocis are very distinct from members of other ciid genera and are relatively uniform morphologically. The genus has been recorded only from well preserved forests in the Neotropical region, from Costa Rica to southern Brazil. We describe Falsocis sooretama sp. nov. based on adult individuals collected at Reserva Biológica de Sooretama (Sooretama, state of Espírito Santo), a conservation unit of the Atlantic Forest biome. Falsocis sooretama sp. nov. is closely related to F. occultus Lopes-Andrade \& Lawrence, but differs from it in possessing sparser stout bristles and very minute setae $(\sim 0.01$ $\mathrm{mm}$ ) on elytra, and apex of anterior male pronotal plate rounded rather than acute. The male genitalia of $F$. sooretama sp. nov. and F. occultus are conspicuously different: in the former the penis is enlarged at apex and the apical lobes of tegmen are not emarginated (each lobe has only a small excavation in the outer edge). Individuals of $F$. sooretama sp. nov. were found inside the basidiomes of an unidentified species of Hymenochaetaceae, possibly belonging to Phellinus. We also provide additional geographic records and an updated identification key to all Falsocis species.
\end{abstract}

KEY WORDS. Brazil, ciid, Ciinae, minute tree-fungus beetles, Neotropical.

Falsocis was described by PIC (1916) based on few specimens of a single species from French Guyana. The diversity of the genus remained unknown until recently, when its morphological limits were redefined and new species were described (LopEs-ANDRADE 2007, Lopes-Andrade \& LAWREnCe 2011). Currently, there are five described species of Falsocis: F. aquilonius Lopes-Andrade \& Lawrence, F. opacus Pic, F. occultus Lopes-Andrade \& Lawrence, F. brasiliensis Lopes-Andrade, and F. egregius Lopes-Andrade \& Lawrence. The genus includes species that range from Costa Rica to southern Brazil, but most species have restricted distribution in the Neotropical region (sensu Morrone 2014).

Species of Falsocis are presently restricted to well preserved forests. As most ciid beetles, larvae and adults of Falsocis spp. are strict fungivores that live inside basidiomes of wood-rotten macrofungi, using them as resource and shelter (Graf-Peters et al. 2011). This study describes F. sooretama sp. nov. from a single locality in southeastern Brazil. Additional geographic records for other species of Falsocis and an updated identification key are also provided.

\section{MATERIAL AND METHODS}

We dissected one male and one female paratype. The terminology for the external morphology and male terminalia of ciids follow mostly Lopes-ANDRADE \& LAWRENCE $(2005,2011)$. The following symbols are used in measurements (in $\mathrm{mm}$ ) and ratios: (BW) basal width of the scutellum; (CL) length of the antennal club (measured from base of the eighth to apex of the tenth antennomere); (EL) elytral length (at midline, from base of scutellum to elytral apex); (EW) greatest elytral width; (FL) length of the antennal funicle (measured from base of the third to apex of the seventh antennomere); (GD) greatest depth of the body (from elytra to metaventrite); (GW) greatest diameter of the eye; (PL) pronotal length along midline; (PW) greatest pronotal width; (TL) total length (= EL+PL, head not included). The ratio GD/EW was recorded as an indication of the degree of convexity; TL/EW indicates the degree of body elongation.

Unless otherwise specified in the text (between square brackets), labels are printed on white paper. Pin label tran- 
scriptions are placed within quotation marks, with each label separated by a backslash. The number and gender of specimens bearing these labels are stated immediately before the label data. Specimens were studied, measured, and photographed under a Zeiss Discovery V20 stereomicroscope equipped with a Zeiss AxioCam 506 digital camera. Final images of the body were the result of joining about 30 slices at different focal lengths using the extended focus module of Zeiss ZEN 1.1.2 software. Whole mount preparations of male terminalia followed the protocol described by LOPES-ANDRADE (2011) and photographs of dissected sclerites were made under a Zeiss AxioLab optic microscope equipped with a Zeiss AxioCamMRc digital camera. The examined specimens belong to the following collections: CELC - Coleção Entomológica do Laboratório de Sistemática e Biologia de Coleoptera, Universidade Federal de Viçosa (Viçosa, Minas Gerais, Brazil); MNHUB - Museum für Naturkunde, Leibniz-Institut für Evolutions und Biodiversitätsforschung an der Humboldt-Universität zu Berlin (Berlin, Germany).

\section{TAXONOMY}

\section{Falsocis sooretama sp. nov.}

Figs. 1-7

urn:Isid:zoobank.org:act:CA01335C-2114-47FF-9229-D24FEC041255

Type locality. Sooretama, state of Espírito Santo, southeastern Brazil $\left(19^{\circ} 23^{\prime} \mathrm{S}, 40^{\circ} 04^{\prime} \mathrm{W}\right)$.

Diagnosis. Falsocis sooretama sp. nov. differs from F. aquilonius and F. opacus in possessing a narrow and not explanate epipleura. It differs from F. brasiliensis and F. egregius in the coarser and denser pronotal punctation, disc punctures separated by less than the width of a puncture, and male pronotal plate rounded at apex, instead of somewhat straight. Falsocis sooretama is closely related to F. occultus, but differs in possessing sparser stout bristles (distant from each other by about five punctures) and very minute setae $(\sim 0.01 \mathrm{~mm})$ on elytra, and apex of anterior male pronotal plate rounded rather than acute. The male genitalia of F. sooretama and F. occultus are conspicuously different: in the former, the penis is enlarged at apex and the apical lobes of tegmen are not emarginated (each lobe has only a small excavation in the outer edge).

Description, male holotype (Figs. 1-3). Measurements in mm: TL 2.05; PL 0.68; PW 1.05; EL 1.36; EW 1.18; GD 0.92. Ratios: PL/PW 0.65; EL/EW 1.15; EL/PL 1.99; GD/EW 0.78; TL/ EW 1.73. Body convex; dorsal and ventral surfaces dark brown; legs reddish brown; mouthparts and antennae yellowish brown; dorsal surface moderately shiny; vestiture of stout yellowish bristles. Head mostly concealed by anterior pronotal projection when seen from above, except for anterolateral angles; frontoclypeal ridge projected forward in a broad lamina, bearing two small tubercles at middle separated by about an eye-width and one short triangular plate at each side. Antennae (left antenna measured; FL $0.26 \mathrm{~mm}$; CL $0.20 \mathrm{~mm}$; CL/FL 0.77) with length of antennomeres (in mm) as follows: $0.08 ; 0.05 ; 0.05 ; 0.03 ; 0.02$; $0.02 ; 0.01 ; 0.06 ; 0.06 ; 0.08$. Eyes coarsely facetted, with about 80 ommattidia; GW $0.15 \mathrm{~mm}$. Pronotum with lateral edges slightly crenulate, bearing a row of stout bristles, not visible for their entire lengths from above, except for part of anterior-lateral angles; anterior margin (beyond anterior angles) explanate, strongly produced forward forming a broad subtriangular plate when seen from above (Fig. 1), conspicuously concave, with apex rounded; punctation single, irregular, coarse and relatively deep, usually separated by a puncture-width or less; surface between punctures moderately shiny and barely microreticulate (almost not visible on disc); punctures comparatively smaller, shallower and more regular on the anterior plate, and microreticulation conspicuous; vestiture of sparse, suberect to decumbent stout yellowish bristles ( $0.03 \mathrm{~mm}$ ), better seen in lateral view (Fig. 2); it is important to note that most punctures bear a very minute seta $(<0.01 \mathrm{~mm})$ only discernible in very high magnification (>300x, with special objective), so difficult to observe that one can consider these punctures as glabrous. Scutellum small, triangular; BW $0.05 \mathrm{~mm}$. Elytra with edges subparallel at their basal two-thirds, posterior sides broadly rounded and apex somewhat blunt; pseudoepipleura tapering from base to basal two-thirds, then continuing as a narrow line; punctation a bit smaller than that of pronotum, more regular and separated by one to two puncture-widths; vestiture consisting of three types of setae: the most frequent one being minute setae $(\sim 0.01 \mathrm{~mm}$ long), barely seen even in high magnifications (more than $300 \mathrm{X})$, the second type consisting of sparse, stout yellowish bristles (0.04-0.05 $\mathrm{mm})$, and the third type being erect slender setae $(0.03 \mathrm{~mm})$; punctures with bristles are less frequent and distant from each other by about five punctures. Hind wings developed, apparently functional. Ventral surfaces of thorax and abdomen finely granulate (Fig. 3). Prosternum flat; prosternal process laminate, almost as long as procoxae. Protibia subparallel-sided; apex devoid of spines and outer apical angle produced into a stout tooth. Meso and metatibia similar to protibia, but comparatively narrower and devoid of outer apical tooth. Metaventrite very short at disc, with discrimen about half of its length. Abdominal ventrites with vestiture of slender decumbent, yellowish setae; punctation shallow, barely visible; length of ventrites (in $\mathrm{mm}$, from base to apex at the longitudinal midline) as follows: $0.24 ; 0.09 ; 0.09 ; 0.09 ; 0.17$; first abdominal ventrite bearing a circular, margined, setose sex patch, located at its center and with a diameter of about one-fifth the length of the ventrite at midline. Male terminalia in paratypes (Figs. 4-7) with sternite VIII (Fig. 4) isosceles trapezoid, with laterals diverging from posterior to anterior angles; posterior angles rounded and bearing several slender setae; posterior edge curved inward and bearing sparse small setae. Basal piece (Fig. 5) nearly two-fifths the length of tegmen. Tegmen (Fig. 6) with posterior portion bearing a deep V-shaped emargination that extends to about the middle of tegmen, forming two lateral lobes; lateral edges slightly curved; anterior one-fifth subtriangular. Penis 

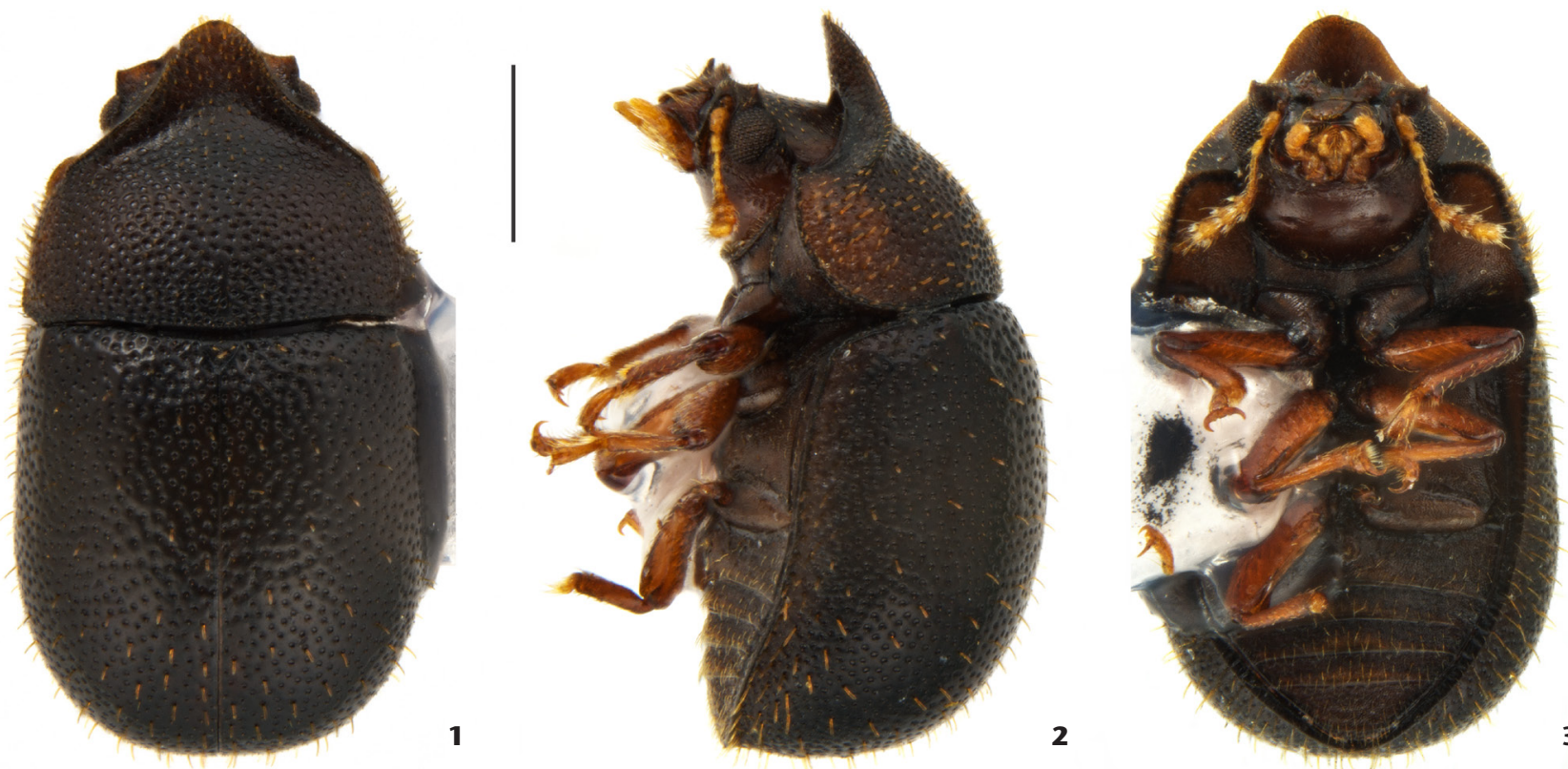

Figures 1-3. Adult male holotype of Falsocis sooretama sp. nov.: (1) dorsal view; (2) lateral view; (3) ventral view. Scale bar: $0.5 \mathrm{~mm}$.

(Fig. 7) about four times as long as broad, subcylindrical, lateral margins parallel in the anterior two-thirds of their lengths, and apex subtriangular and membranous.

Variation. Males, measurements in $\mathrm{mm}(\mathrm{n}=08$, including the holotype): TL 1.66-2.26 (1.09 \pm 0.17); PL 0.57-1.00 (0.73 \pm 0.14); PW 1.01-1.19 (1.07 \pm 0.06); EL 0.92-1.36 (1.20 \pm 0.15$)$; EW 1.00-1.25 (1.11 \pm 0.08$)$; GD 0.76-0.94 (0.89 \pm 0.06$)$. Ratios: PL/PW 0.53-0.84 (0.68 \pm 0.10); EL/EW 0.83-1.21 (1.08 \pm 0.14$)$; EL/PL 1.23-1.99 (1.69 \pm 0.45); GD/EW 0.74-0.85 (0.80 \pm 0.04$)$; TL/EW 1.50-1.93 (1.74 \pm 0.13$)$. Females, measurements in $\mathrm{mm}$ $(\mathrm{n}=14)$ : TL 1.64-2.08 (1.87 \pm 0.15$) ;$ PL 0.51-0.78 (0.62 \pm 0.08$)$; PW 0.61-1.13 (0.93 \pm 0.17); EL 1.01-1.50 (1.25 \pm 0.13$)$; EW 0.981.24 (1.16 \pm 0.10$)$; GD 0.76-1.14 (0.92 \pm 0.11$)$. Ratios: PL/PW 0.48-0.78 (0.62 \pm 0.07$) ; \mathrm{EL} / \mathrm{EW} 0.92-1.15$ (1.08 \pm 0.07$) ; \mathrm{EL} / \mathrm{PL}$ $1.52-2.42(2.04 \pm 0.36) ; \mathrm{GD} / \mathrm{EW}$ 0.77-0.97 (0.81 \pm 0.09$) ; \mathrm{TL} / \mathrm{EW}$ $1.50-1.83(1.61 \pm 0.08)$.

Type series. BraziL: Espírito Santo, Sooretama, male holotype (CELC), labeled "Brasil: ES Sooretama, Reserva Biológica de Sooretama 30.XI.2011 leg. L. S. Araujo [printed] \Código Trans.: Parcela: Fungo: [printed] 2 E 1 [handwritten] $\backslash$ Falsocis sooretama Araujo \& Lopes-Andrade HOLOTYPUS [printed on red paper]". Paratypes: 7 males (1 dissected) and 14 females (CELC), same locality data as holotype and additionally labeled $\backslash$ Falsocis sooretama Araujo \& Lopes-Andrade PARATYPUS [printed on yellow paper] $\backslash$. Among the paratypes, 1 female was collected together with the holotype (collection code " $2 \mathrm{E} 1$ ") and is labeled accordingly, 1 female (very damaged, found dead in the basidiome) is labeled "Código: Trans.: Parcela: Fungo: [printed] 1 B 2 [handwritten]", and the males and 12 females are labeled
"Código: Trans.: Parcela: Fungo: [printed] 2 B 1 [handwritten]". Host fungus. The holotype and one female (collection code " 2 E 1") were found in a large basidiome $(\sim 15 \mathrm{~cm}$ of diameter) of Hymenochaetaceae, possibly a species of Phellinus. Most paratypes (code "2 B 1") were found in a basidiome similar in size and possibly belonging to the same fungus species. A fully pigmented female was found in Ganoderma sp. (code "1 B 2", basidiomes in very advanced decaying stage), possibly an unsuccessful colonization of the fungus and thus we prefer not to consider this as a host record.

Etymology. The specific epithet is a name in apposition referring to Sooretama, in the state of Espírito Santo (southeast Brazil), terra typica of the species. The word "Sooretama" comes from the Tupi language and means "land and shelter for forest animals" (from "soo", "çoó" - animal, hunt; and "retama" place, land, motherland).

Remarks. This new species is known only from the type locality, found in three samples from "Reserva Biológica de Sooretama", a conservation unit of about 24,000 ha of Atlantic Forest. Most specimens (collection code "2 B 1") were reared in the laboratory in the basidiome they were collected, without adding any other substrate. Specimens of this new species were firstly identified as F. occultus. However, when we dissected and examined the sclerites of the male terminalia, we realized that it is a distinct species. Among the reared specimens, we also found a teneral and three fully pigmented males of $F$. brasiliensis, making this the first record of two different species of Falsocis found in the same individual fungus. Falsocis sooretama sp. nov. seems to be closely related to F. occultus, and they are barely discern- 

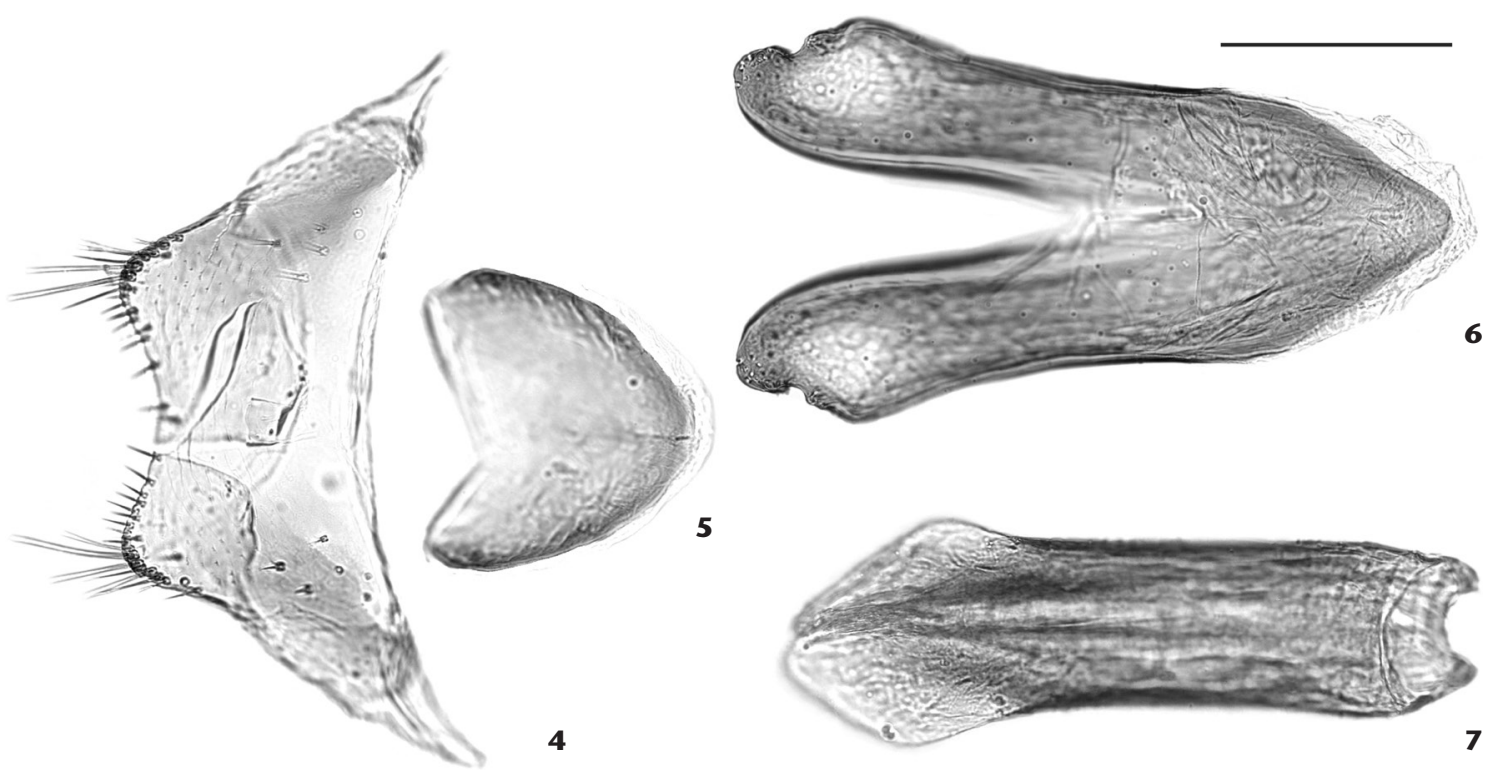

5

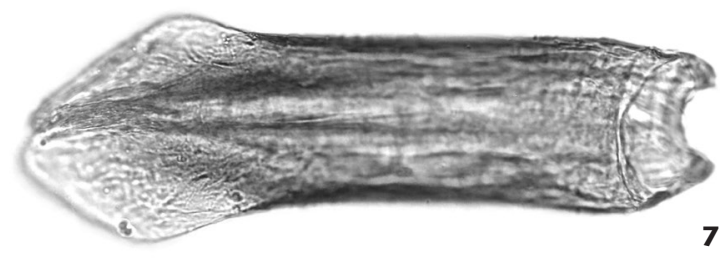

Figures 4-7. Dissected male terminalia of a paratype of Falsocis sooretama sp. nov.: (4) sternite VIII; (5) basal piece; (6) tegmen; (7) penis. Scale bar: $0.1 \mathrm{~mm}$.

ible before careful examination. Besides the diagnostic features mentioned above, F. occultus is distinct by the comparatively larger elytral bristles $(0.07-0.08 \mathrm{~mm}$ long, not $0.1 \mathrm{~mm}$ as cited in the original description, the difference due to microscope resolution and magnification capacity) and minute setae (0.03 $\mathrm{mm}$ long). In F. sooretama, elytral bristles are 0.04-0.05 mm long and minute setae about $0.01 \mathrm{~mm}$, the latter being decumbent and only discernible in very high magnification ( $>300 \mathrm{X})$. Interestingly, in F. sooretama a third type of seta is discernible, which is erect, slender and about $0.03 \mathrm{~mm}$ long, but much less frequent than minute setae.

\section{Additional data on Falsocis species}

\section{Falsocis brasiliensis Lopes-Andrade, 2007}

Additional material. BRAzIL: Rio de Janeiro, Itatiaia, 1 male and 3 females (CELC) labeled "BRASIL: RJ Itatiaia, Parque Nacional de Itatiaia; 09.XI.2011 leg. L.S. Araujo", these specimens being additionally labeled as follows: 1 female \Código: Trans.: Parcela: Fungo: [printed] 3 C 2 [handwritten]", 1 male and 1 female "Código: Trans.: Parcela: [printed] EXTRA [handwritten]" and 1 female (CELC) labeled "T3 PA F1"; BrazIL: Minas Gerais, Viçosa, 1 male and 1 female (CELC) labeled "BRASIL: MG Viçosa, Mata do Paraíso; 28.I.2011 leg. L. S. Araujo \T1 PC F2"; BraziL: Espírito Santo, Sooretama, 1 teneral male (CELC) and 3 pigmented males (CELC, in alcohol) labeled "BRASIL: ES Sooretama, Reserva Biológica de Sooretama 30.XI.2011 leg. L. S. Araujo\Código: Trans.: Parcela: Fungo: [printed] 2 B 1 [handwritten]".

Host fungi. The specimens from "Parque Nacional de Itatiaia" were found in Hymenochaete luteobadia (Fr.) Höhn. \&
Litsch. (1907) (collection code "3 C 2"), Hymenochaete sp. (not identified to species level because it was in an advanced decaying stage; collection code "3 A 1"). The specimens from "Mata do Paraíso" were found in H. luteobadia. The specimens from "Reserva Biológica de Sooretama" were found in Hymenochaetaceae, possibly a Phellinus sp., and together with F. sooretama. The presence of a teneral male in this basidiome indicates that this specimen, and possibly the other three males, bred in this basidiome, which led us to consider it a host record. Available host-fungi records for $F$. brasiliensis indicate that it is monophagous, usually associated with basidiomes of Hymenochaete (Lopes-Andrade \& Lawrence 2011, Saurat et al. 2015). This single host record in Phellinus sp. indicates that the species may breed in alternative hosts of the same fungus family (Hymenochaetacea), but Hymenochaete, especially H. luteobadia, is the main host (Graf-Peters et al. 2011, Lopes-Andrade \& Lawrence 2011, SAURAT et al. 2015).

Remarks. By the time of its description, F. brasiliensis was thought to be restricted to three fragments of the Atlantic Forest in Brazil (Lopes-Andrade 2007). A few years later, it was recorded from another Atlantic Forest fragment located in Santa Maria do Jetibá, state of Espírito Santo (Lopes-ANDRADE \& LAWRENCE 2011). In the same work, F. brasiliensis was recorded from "Belvedere", which is indeed the lower portion of the forest fragment "Mata da Biologia", the type-locality of the species (Viçosa, state of Minas Gerais). Here we provide records from other three fragments of the Atlantic Forest, all of which are conservation units in southeast Brazil: "Mata do Paraíso" (the whole name being "Estação de Pesquisa e Treinamento em Educação Ambiental - EPTEA Mata do Paraíso"), located about 
$15 \mathrm{Km}$ from the type-locality; "Parque Nacional do Itatiaia", state of Rio de Janeiro; and "Parque Estadual de Sooretama", state of Espírito Santo, collected in the same basidiome of F. sooretama. Recently, F. brasiliensis was also found in French Guyana inside a basidiome of Hymenochaete sp. (SAURAT et al. 2015). It is worth mentioning that the species is not frequently collected, and the new records provided here were the result of an intense collecting effort of fungivorous beetles in Atlantic Forest fragments (Araujo et al. 2015).

\section{Falsocis occultus Lopes-Andrade \& Lawrence, 2011}

Additional material. Brazil: Rio de Janeiro, Petrópolis, 1 male and 1 female (MNHUB) labeled "Petropolis 17.10.[18]98\ Falsocis occultus Lopes-Andrade \& Lawrence, 2011 det. C. Lopes-Andrade 2012".

Remarks. The abovementioned specimens from MNHUB are historical material collected in the end of the XIX century. Attempts to recollect the species in Petrópolis and adjacent localities in the state of Rio de Janeiro were unsuccessful (the most recent collecting effort is part of the work of ArAUjo et al. 2015). It is worth mentioning that most known specimens of F. occultus belong to the type series, from a single collection in the type locality (Linhares, state of Espírito Santo). Besides these, $F$. occultus is known only from a single male collected in 1940 at Nova Teutônia, state of Santa Catarina (Lopes-ANDRADE \& LAWRENCE 2011) and the couple reported here from Petrópolis, collected in 1898. Recent collections in south Brazil, in a well preserved forest in São Francisco de Paula, state of Rio Grande do Sul, did not reveal any F. occultus (Graf-Peters et al. 2011). Future works should evaluate whether F. occultus is extinct in the Brazilian South.

\section{Updated identification key to Falsocis species}

1. Epipleura enlarged posteriorly, forming a slightly or strongly explanate posterolateral edge in elytra, conspicuously or barely visible from above...

....2

1 '. Epipleura narrowing to apex, forming a narrow, not explanate, posterolateral edge in elytra, not visible from above........... 3

2. Pronotum with lateral edges explanated, completely visible from above. Posterior elytral edge (outer edge of epipleura) simple (not crenulate), barely visible from above. Known from Panamá, Costa Rica, and Colombia.

Falsocis aquilonius Lopes-Andrade \& Lawrence, 2011

2 '. Pronotum with lateral edges narrow, not visible from above except for anterior and posterior corners. Posterior elytral edge (outer edge of epipleura) crenulate, easily visible from below and above. Known from northern Brazil (Altamira, state of Pará) and French Guyana .....

Falsocis opacus Pic, 1916

3. Pronotal punctation deep and coarse, with punctures usually separated by half a puncture-width or less at disc. Anterior plate of pronotum in males with apex acute or broadly rounded, bearing a patch or row of stout bristles shorter than half an eye-width

3 '. Pronotal punctation shallow and fine, with punctures usually separated by about a puncture-width at disc. Anterior plate of pronotum in males with apex straight, barely emarginated or slightly rounded, bearing slender setae usually as long as to twice as long (or more) than an eye-width.

4. Elytral vestiture conspicuously dense, punctures bearing stout bristles (0.07-0.08 $\mathrm{mm})$, separated from each other by one to two punctures, the latter punctures bearing minute setae $(\sim 0.03 \mathrm{~mm})$. Anterior pronotal plate in males ending in acute apex, even in small males. Known from the coastal Atlantic Forest from southeastern to south Brazil ......

............. Falsocis occultus Lopes-Andrade \& Lawrence, 2011

4 '. Elytral vestiture sparse, punctures bearing stout bristles $(0.04$ $0.05 \mathrm{~mm}$ ) separated from each other by about five punctures, the latter punctures bearing minute inconspicuous setae $(\sim 0.01 \mathrm{~mm}$; there is a third type of vestiture of slender setae $\sim 0.03 \mathrm{~mm}$ ), but very sparse. Anterior pronotal plate in males ending in a rounded apex (a bit angulate in large males, but never acute). Known only from the type locality (Sooretama, Espírito Santo, Brazil)................ Falsocis sooretama sp. nov.

5. Anterior pronotal angles distinctly produced forward and somewhat acute. Males with head devoid of conspicuous projection behind each eye; long setae of anterior pronotal plate organized into two tufts. Known from French Guyana and the Atlantic Forest in Brazil.

Falsocis brasiliensis Lopes-Andrade, 2007

5'. Anterior pronotal angles barely produced forward and rounded. Males with head bearing a conspicuous triangular plate, projected outward, behind each eye; long setae of anterior pronotal plate organized as a row, not forming tufts. Known only from the type locality, Santarém (Pará, Brazil) ............. .Falsocis egregius Lopes-Andrade \& Lawrence, 2011

\section{ACKNOWLEDGEMENTS}

We thank Vivian E. Sandoval Gómez for searching and photographing types and other historical specimens in European museums, and Benoît Dodelin and Remy Saurat for sharing information on F. brasiliensis from French Guyana. Field collections in Brazil were registered and licensed by Instituto Chico Mendes de Conservação da Biodiversidade (ICMBio, Ministério do Meio Ambiente). This work was supported by Fundação de Amparo à Pesquisa do Estado de Minas Gerais (FAPEMIG: Edital Universal APQ-00653-12; Edital Programa Pesquisador Mineiro PPM-00026-14), Coordenação de Aperfeiçoamento de Pessoal de Nível Superior (CAPES: post-doctoral grant to LSA, process 88881.030447/2013-01), and Conselho Nacional de Desenvolvimento Científico e Tecnológico (CNPq: Edital Universal 479737/2012-6; LSA grant 140084/2010-0; research grant to CLA 302480/2012-9). 


\section{LITERATURE CITED}

Araujo LS, Komonen A, Lopes-Andrade C (2015) Influences of landscape structure on diversity of beetles associated with bracket fungi in Brazilian Atlantic Forest. Biological Conservation 191: 659-666. doi: 10.1016/j.biocon.2015.08.026

Graf-Peters LV, Lopes-Andrade C, Silveira RMB, Moura LA, Reck MA, Nogueira-de-SÁ F (2011) Host fungi and feeding habits of Ciidae (Coleoptera) in a subtropical rainforest in Southern Brazil, with an overview of host fungi of Neotropical ciids. Florida Entomologist 94(3): 553-566. doi: 10.1653/024.094.0320

Lopes-Andrade C (2007) Notes on Falsocis Pic (Coleoptera: Tenebrionoidea: Ciidae), with the description of an endangered Brazilian species. Zootaxa 1544: 41-58.

Lopes-Andrade C (2011) The first Strigocis Dury (Coleoptera, Ciidae) from the southern Neotropical region and a provi-

Submitted: 19 October 2015

Received in revised form: 4 December 2015

Accepted: 28 December 2015

Editorial responsibility: Gabriel L.F. Mejdalani sional key to world species. ZooKeys 81: 27-37. doi: 10.3897/ zookeys.81.940

Lopes-Andrade C, Lawrence JF (2005) Phellinocis, a new genus of Neotropical Ciidae (Coleoptera: Tenebrionoidea). Zootaxa 1034: 43-60.

Lopes-Andrade C, LaWrence JF (2011) Synopsis of Falsocis Pic (Coleoptera, Ciidae), new species, new records and an identification key. ZooKeys 145: 59-78. doi: 10.3897/zookeys.145.1895

Morrone JJ (2014) Biogeographical regionalisation of the Neotropical region. Zootaxa 3782(1): 1-110. doi: 10.11646/ zootaxa.3782.1.1

PIC M (1916) Diagnoses génériques et spécifiques. Mélanges Exotico-Entomologiques 18: 1-20.

Saurat R, Dodelin B, Dalmon J (2015) Première observation de Falsocis brasiliensis (Coleoptera: Ciidae) em Guyane. France, ACOREP, Coléoptères de Guyane, Tome IX, p. 3-4.

Author contributions: LSA and CLA participated equally in the preparation of this article.

Competing interests: The authors have declared that no competing interests exist. 